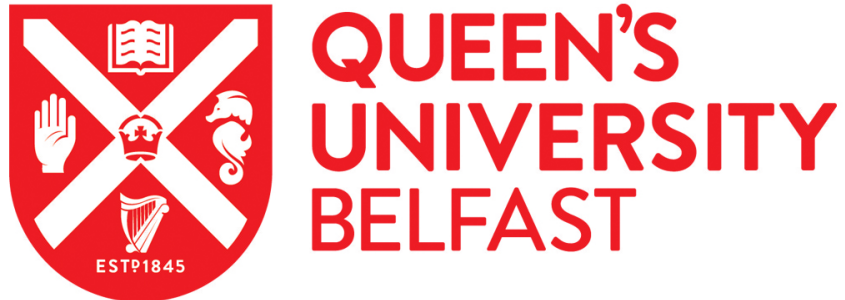

\section{Colourimetric plastic film indicator for the detection of the volatile basic nitrogen compounds associated with fish spoilage}

Wells, N., Yusufu, D., \& Mills, A. (2019). Colourimetric plastic film indicator for the detection of the volatile basic nitrogen compounds associated with fish spoilage. Talanta, 194, 830-836.

https://doi.org/10.1016/j.talanta.2018.11.020

\section{Published in:}

Talanta

\section{Document Version:}

Peer reviewed version

Queen's University Belfast - Research Portal:

Link to publication record in Queen's University Belfast Research Portal

\section{Publisher rights}

Copyright 2018 Elsevier.

This manuscript is distributed under a Creative Commons Attribution-NonCommercial-NoDerivs License

(https://creativecommons.org/licenses/by-nc-nd/4.0/), which permits distribution and reproduction for non-commercial purposes, provided the author and source are cited.

\section{General rights}

Copyright for the publications made accessible via the Queen's University Belfast Research Portal is retained by the author(s) and / or other copyright owners and it is a condition of accessing these publications that users recognise and abide by the legal requirements associated with these rights.

Take down policy

The Research Portal is Queen's institutional repository that provides access to Queen's research output. Every effort has been made to ensure that content in the Research Portal does not infringe any person's rights, or applicable UK laws. If you discover content in the Research Portal that you believe breaches copyright or violates any law, please contact openaccess@qub.ac.uk. 


\title{
Colourimetric plastic film indicator for the detection of the volatile basic nitrogen compounds associated with fish spoilage
}

\author{
Nathan Wells, Dilidaer Yusufu, and Andrew Mills*, \\ School of Chemistry and Chemical Engineering, Queen's University Belfast, Stranmillis Road, \\ Belfast BT9 5AG, UK: \\ e-mail address: andrew.mills@qub.ac.uk
}

\begin{abstract}
The first example of an extruded polymer film containing the $\mathrm{pH}$ sensitive dye bromophenol blue (BPB) is described in which the polymer encapsulated dye changes colour from yellow to blue upon exposure to basic volatile nitrogen compounds, such as those given off by fish as it spoils. The latter include: trimethylamine (TMA), dimethylamine (DMA) and ammonia $\left(\mathrm{NH}_{3}\right)$, and are collectively known as total volatile basic nitrogen (TVB-N). The films' colourimetric response to specific levels of TMA, as measured using absorbance spectroscopy and digital photography coupled with RGB colour analysis, is reported. The indicator is then used as a fish spoilage indicator at 22 and $4{ }^{\circ} \mathrm{C}$, whilst at the same time a microbiological study is carried out, and in both cases the results reveal a strong correlation between the change in colour of the indicator with the concentration of bacterial colony forming units on the fish; the latter is often used as a measure of fish freshness. The correlation arises because the increase in TVB-N in head space of the package is due to the gradual bacteria-induced decomposition of the fish. The colourimetric TVB-N plastic film indicator's potential as a spoilage indicator for packaged fresh fish is discussed briefly.
\end{abstract}

Key words: ammonia; amine; indicator; extrusion; colour; fish; freshness 


\section{Introduction}

Intelligent packaging is 'a packaging system that is capable of carrying out intelligent functions (such as detecting, sensing, recording, tracing, communicating, and applying scientific logic) to facilitate decision making to extend shelf life, enhance safety, improve quality, provide information, and warn about possible problems' [1]. Often the sensing part of intelligent packaging involves at least one fluorometric or colourimetric indicator that responds to an important packaging parameter [2], such as: the combination of time \& temperature [3], or the presence and level of a gas (wanted or unwanted) inside the package, such as: $\mathrm{CO}_{2}$ [4], $\mathrm{O}_{2}$ [5], volatile amines [6] or ammonia [7]. Colourimetric indicators are generally less common than their fluorometric counterparts [8], but have the advantage that they can be readily assessed by eye or using digital image technology which is now commonly available and inexpensive $[9,10]$. Intelligent packaging is particularly relevant to the fisheries industries which face ever-increasing regulative constraints relating to the safety and traceability of fresh and processed fish [11]. As a consequence, there is a real need in the fish industries for a simple, easy to use, inexpensive method for determining fish freshness after packaging, i.e. a quality control indicator for packaged fish $[6,11,12]$. Such an indicator would be a useful quality control tool as the packaged product makes its way from the packager to the retailer and then onto the customer [13].

A European Union recognised indicator of freshness is the total volatile basic nitrogen (TVB-N) present in the flesh of fish [14], due to volatile amines, such as trimethyl amine (TMA), dimethyl amine (DMA) and ammonia $\left(\mathrm{NH}_{3}\right)$, that are responsible for the characteristic 'fishy' odour associated with spoiled fish; the EU TVB-N spoilage threshold is $35 \mathrm{mg}$ per $100 \mathrm{~g}$ of flesh, anything above this level is deemed as unsuitable for consumption [11]. TVB-N level is a measure of fish freshness because food spoilage bacteria are responsible for the generation of the volatile amines and ammonia via the metabolic breakdown of amino acids in fish flesh [12]. Although a world-wide standard of fish freshness, the usual method for measuring the TVB-N level in fish involves a number of complicated steps and titrations which take typically $4 \mathrm{~h}$ for one analysis [15].

Given the relationship that exists between TVB-N and bacteria levels, it is not surprising therefore, that another popular measure of fish freshness is the level of bacteria present in the fish. The surface microbial population on a test sample, assessed by taking swabs, is called the total viable count (TVC), with units of: colony forming units (cfu) [16] and it is usually suggested that fish is no longer safe to eat once the measured TVC level exceeds $10^{7} \mathrm{cfu} \mathrm{g}^{-1}$ [17]. Note, however, that exact spoilage thresholds, i.e. the TVB-N and TVB levels employed to identify spoiled fish, can vary greatly since they depend on season, maturity and, in particular, species [18]. Unfortunately, the measurement of TVB- 
$\mathrm{N}$, or TVC levels, is non-trivial, time-consuming and destructive of the sample and/or package and so $100 \%$ quality assurance (QA) of packaged fish is not possible, and so QA is limited to regular sampling, usually at the packaging stage. It follows from the above discussion that a simple, inexpensive, disposable, non-toxic, quantitative indicator of either of these parameters would benefit greatly the fisheries industries and consumer.

Relevant to the development of a TVB-N colorimetric ink-based sensor is the fact that this group [19] and others [20] have reported the development of ammonia indicators, based on the response of a $\mathrm{pH}$ indicator dye via the following simple colour-changing general reaction:

$$
\begin{aligned}
\mathrm{RNH}_{2}+\mathrm{DH} \rightleftharpoons & \mathrm{RNH}_{3}{ }^{+} \mathrm{D}^{-} \\
\text {Colour } \mathrm{A} & \text { Colour B }
\end{aligned}
$$

where $\mathrm{R}=\mathrm{H}$ and $\mathrm{DH}$ and $\mathrm{D}^{-}$are the differently coloured protonated and deprotonated forms of a $\mathrm{pH}$ dye, respectively. Not surprisingly, this system is also sensitive to volatile amines, where $\mathrm{R}$, in reaction (1), is usually an alkyl group, and so has led to their use by others [6, 12, 17, 21-25] as fish freshness indicators based on the assumption that the colour change exhibited by the indicator can be used to identify either the TVB-N $[17,25]$, or TVC $[6,12,23,25]$, threshold level. To date, a typical fish freshness indicator, based on reaction (1), comprises a $\mathrm{pH}$ indicator dye encapsulated in a watersoluble polymer medium ( $E P$ = encapsulation polymer) and covered by a gas-permeable, ionimpermeable, membrane (GPM) so as to prevent dye leaching from the indicator film into the food package itself. The latter feature, if exhibited, is obviously completely unacceptable and yet not at all unlikely without a GPM isolating layer since the inks used to make the TVB-N indicator films are usually water-based, and all fresh packaged fish has a water activity coefficient ca. 0.99 [26], so that the relative humidity, $\mathrm{RH}$, inside the package is ca. $100 \%$, making water contact with the label likely, either through direct contact with the fish or via condensate on all the interior surfaces of the package, including the lidding and any indicator that may be placed there.

Monitoring the change in colour of the indicator is usually carried out using absorbance spectroscopy or via $\mathrm{L}^{*} \mathrm{a} * \mathrm{~b}$ chromaticity measurements. The former technique is ideal for carrying out quantitative analysis of reaction (1) via the concentrations of $\mathrm{DH}^{2}$ and $\mathrm{D}^{-}$, i.e. [DH] and [D-], respectively, but is relatively expensive and not conducive to the routine and rapid analysis of an indicator incorporated inside a food package. In contrast, chromaticity measurements are much simpler and cheaper to make, as is digital image colour analysis, but, often when used, the relationship between absorbance and the colour measuring parameter is rarely established and so cannot be used to extract out relative values of the $[\mathrm{DH}]$ and $\left[\mathrm{D}^{-}\right]$and so probe reaction (1) in a quantitative manner. Instead, colour analysis methods are almost always employed simply to construct a calibration graph relating the measured 
colour parameter to the concentration of the analyte of interest, such as ammonia or TMA, but rarely correlated to the actual TVB-N or TVC levels in the fish, as noted for most entries in Table 1, which lists most of the fish freshness indicators that have been reported to date. Note: in only one case [25] is the sensor response correlated to the measured TVB-N and TVC in the fish.

In a recent paper, this group reported a naked, i.e. no additional GPM layer, low density polyethylene (LDPE) plastic colour-based sensor for $\mathrm{CO}_{2}$, which was created by blending in an extruder, LDPE with a $\mathrm{CO}_{2}$-sensitive pigment, comprising a coating of a colour-based $\mathrm{pH}$-sensitive, dye (thymol blue) on nanoparticles (principal particle size, ca. $\sim 20 \mathrm{~nm}$ ) of hydrophilic, fumed silica [27]. The $\mathrm{CO}_{2}$-sensitive indicator plastic film used was tested using both gaseous and dissolved $\mathrm{CO}_{2}$ and, importantly, in the latter case showed no signs of dye leaching into the aqueous solution because the LDPE encapsulation medium acts as an intrinsic gas-permeable membrane. The stability of these plastic film $\mathrm{CO}_{2}$ indicators in aqueous solution is in marked contrast to $\mathrm{CO}_{2}$ based ink films which tend to lose dye in aqueous solution and so require a GPM $[27,28]$. Since polymer film extrusion is a very simple, easily scaled-up process, it follows that such indicator films are inexpensive to manufacture and, indeed, this technology forms the basis of the 'After Opening Freshness' indicator label recently produced by Insignia Technologies Ltd. and currently being trialled by Sainsbury's on their fresh ham packages [29, 30].

The above work suggests that it should also be possible to make an extruded plastic indicator film for ammonia and volatile amines, which does not require an additional gas permeable membrane unlike the ink indicators in Table 1, and, like the $\mathrm{CO}_{2}$ plastic film indicators reported recently [27], will be inexpensive to mass produce and easy to use. Thus, this paper describes, for the first time, the production and characterisation of a new colourimetric extruded plastic film indicator, which has no need for an additional GPM layer, for the detection of the volatile amines and ammonia and its subsequent use as a potential fish spoilage indicator. 


\section{Table 1 - Reported amine/TVB-N indicators}

\begin{tabular}{|c|c|c|c|c|c|c|c|}
\hline Dye & EP & GPM & $\begin{array}{c}\mathrm{T} \\
\left({ }^{\circ} \mathrm{C}\right)\end{array}$ & $\begin{array}{l}\text { Analytical } \\
\text { method }^{a} \quad \text { (for } \\
\text { indicator) }\end{array}$ & $\begin{array}{l}\text { Spoilage } \\
\text { measurement }\end{array}$ & Comments & ref \\
\hline BCG & CA & PTFE & 20 & $\begin{array}{l}\text { Reflectance } \\
\text { colorimetry }\end{array}$ & $\mathrm{Cfu}$ & $\begin{array}{l}\text { 2006/2007. Sensor optical response determined as a function of ammonia, but not } \\
\text { correlated to TVB-N. Colour change starts as the fish spoilage reaches } 10^{7} \mathrm{cfu} \mathrm{g}^{-1} \text {. Cod, } \\
\text { grenadier and whiting spoilage are studied. }\end{array}$ & $\begin{array}{l}{[6,} \\
12]\end{array}$ \\
\hline BCG & $\mathrm{CA}$ & PTFE & $\begin{array}{c}19- \\
21\end{array}$ & $\begin{array}{l}\text { Chromaticity (CIE } \\
L^{*} a * b \quad \text { colour } \\
\text { space) }[21]\end{array}$ & $\mathrm{Cfu}$ & $\begin{array}{l}\text { 2014. Largely same indicator as above, although no PTA added, but this time a reflectance } \\
\text { spectrometer is used to make the optical measurements necessary to allow the calculation } \\
\text { of the colour difference parameter, } \Delta \mathrm{E}^{*} \text { [22]. Sensor response determined as a function of } \\
\text { the concentration of TMA in solution via the level of TMA in the vapour, although the actual } \\
\text { TMA level in vapour was not determined. Fish spoilage (via TVC) was also measured, but } \\
\text { no attempt made to correlate with optical response. The work is focussed on the spoilage } \\
\text { of mackerel. }\end{array}$ & {$[23]$} \\
\hline $\begin{array}{l}\text { BCG } \\
\text { and } \\
\text { other } \\
\text { dyes }\end{array}$ & $\begin{array}{l}\text { Silica } \\
\text { gel }\end{array}$ & none & $\begin{array}{l}4 \\
\text { and } \\
20\end{array}$ & $\begin{array}{l}\text { Colour response } \\
\text { converted to grey } \\
\text { scale intensity. }\end{array}$ & Cfu and TVB-N & $\begin{array}{l}\text { 2016. Indicator dyes on silica gel plates used to create an array of indicators. Colour of } \\
\text { different indicators determined using a flatbed scanner. Reported TVB-N levels in fish } \\
\text { correlate with the optical response of the indicator arrays, although no calibration graph } \\
\text { given. Atlantic salmon spoilage is studied here. }\end{array}$ & [17] \\
\hline $\begin{array}{l}\text { BTB/ } \\
\text { PR }\end{array}$ & $\begin{array}{l}\text { Not } \\
\text { given }\end{array}$ & PET & $\begin{array}{l}4, \\
10 \\
20\end{array}$ & $\begin{array}{l}\text { Chromaticity (CIE } \\
\text { L*a*b colour } \\
\text { space) }[21]\end{array}$ & $\begin{array}{c}\mathrm{NH}_{3} \text { (by gas } \\
\text { chromatography) }\end{array}$ & $\begin{array}{l}\text { 2016. The colour difference parameter } \Delta \mathrm{E}^{*} \text { is linearly correlated with ammonia } \\
\text { concentration. Indicator changes colour as fish spoils but no attempt made to relate colour } \\
\text { change to TVC or TVB-N in fish. Skate spoilage studied. }\end{array}$ & [24] \\
\hline $\begin{array}{l}\text { AC- } \\
\text { beads }\end{array}$ & none & none & $\begin{array}{l}4, \\
25\end{array}$ & $\begin{array}{l}\text { Chromaticity (CIE } \\
L^{*} a * b \quad \text { colour } \\
\text { space) }[21]\end{array}$ & Cfu and TVB-N & $\begin{array}{l}\text { 2018. Beads fixed to lid of closed petri dish containing fish. } \Delta \mathrm{E}^{*} \text { correlated to TVB-N content } \\
\text { and variation in bacterial populations. Rainbow trout spoilage is studied. }\end{array}$ & {$[25]$} \\
\hline
\end{tabular}

a: always as a measure of TVB-N level in gas phase of packaging

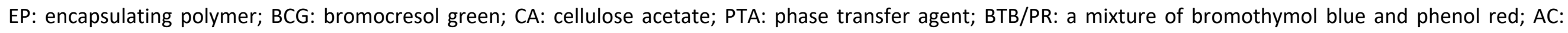
anthocyanin (red cabbage dye) in alginate beads; PTFE: polytetrafluoroethylene; PET: polyethylene terephthalate. 


\section{Experimental}

\subsection{Materials}

All chemicals were purchased from Sigma Aldrich, unless otherwise stated, and in the highest purity available. All solutions were prepared on the day, and all aqueous solutions were made up using double-distilled and deionised water. The gases were purchased from BOC. The fine, low-density polyethylene, LDPE, powder $(\mathrm{MFI}=20)$ used for preparing the masterbatch was supplied by PW Hall (Glasgow). The $\mathrm{SiO}_{2}$ (Aerosil ${ }^{\circledR} 130$ hydrophilic fumed silica) nanoparticles, used to make the TVB-N sensitive pigment, was a gift from Evonik (BET surface area $=130 \pm 25 \mathrm{~m}^{2} \mathrm{~g}^{-1}$, particle size ca. $\sim 20 \mathrm{~nm}$ ). The cod fillets used to test the indicator film and in the assessment of the degree of microbiological spoilage with storage time, were purchased from a local branch of the supermarket chain Tesco plc and used on the day of purchase, with a best before date 3 days in advance of their use.

\subsection{TVB-N pigment preparation}

In a $120 \mathrm{~cm}^{3}$ beaker were placed $100 \mathrm{~cm}^{3}$ of an aqueous dispersion of $2 \mathrm{~g}$ of Aerosil ${ }^{\circledast}$ hydrophilic silica, followed by $0.2 \mathrm{~g}$ of the protonated form of the $\mathrm{pH}$ indicating dye, bromophenol blue (BPB), i.e. HBPB; $\mathrm{BPB}$ has a $\mathrm{pK}_{\mathrm{a}}=3.85$ [31]. The mixture was sonicated for 10 minutes in an ultrasonic bath to dissolve the dye and produce a homogeneous dispersion of the particles; the resulting clear, yellow-coloured suspension was then stirred vigorously using a magnetic stirrer for 2 hours. A bright yellow, dry powder pigment, comprising Aerosi ${ }^{\circledR}$ hydrophilic silica particles coated with $\mathrm{BPB}$, was then obtained by spray-drying the suspension using a Buchi Mini Spray Dryer B-290. This pigment responds to the presence of volatile nitrogen species, such as ammonia or volatile amines, by turning from an initial bright yellow colour to dark blue, due to reaction (1). Photographs of the pigment before and after exposure to trimethyl amine (TMA) vapour are illustrated in the supplementary information, figure S1. The colouration of the pigment upon exposure to TMA vapour is virtually instantaneous, and, under quiescent, ambient conditions, the pigment recovers its original colour after ca. $24 \mathrm{~h}$, once the source of TMA has been removed.

\subsection{TVB-N indicator preparation}

The BPB-coated hydrophilic silica pigment was blended in a 1:9 $(\mathrm{w} / \mathrm{w})$ ratio with fine LDPE powder until a uniform yellow colour was achieved. This $10 \mathrm{wt} \%$ pigmented polymer powder was then pelletised using a Rondol Microlabs Twinscrew extruder, with operating temperatures of 90, 115, 125, 135 and $125^{\circ} \mathrm{C}$ for the feed, zones $1-3$ and pelletising die, respectively, and a pigment/LDPE mixture feed hopper rate of $41 \mathrm{rpm}$. The extruder screw speed was $80 \mathrm{rpm}$ and the pelletizer speed was 0.5 $\mathrm{m} \mathrm{min}{ }^{-1}$. The resulting pellets were then re-extruded as pellets to ensure that the pigment was 
dispersed evenly throughout the LDPE polymer encapsulating material. These pellets were then extruded into a thin, clear yellow-coloured plastic film (ca. $42 \pm 2 \mu \mathrm{m}$ ), with $10 \mathrm{wt} \%$ pigmentation using the Rondol Microlabs Twinscrew extruder, with operating temperatures of $90^{\circ} \mathrm{C}$, increasing to 110 $125-135^{\circ} \mathrm{C}$ and finally $140^{\circ} \mathrm{C}$ for the feed, zones $1-3$ and the sheet die, respectively. The film was cut into $25 \mathrm{~mm}$ diameter discs for testing. As illustrated in figure S2 of the supplementary information, when exposed to a stream of argon gas, which had previously passed through a 4 wt\% aqueous solution of trimethyl amine (TMA), the indicator film changed from yellow to blue in about $21 \mathrm{~min}$, due to reaction (1), where $\mathrm{DH}$ is the protonated form of the $\mathrm{pH}$ indicating dye, i.e. yellow-coloured $\mathrm{HBPB}$, and $\mathrm{D}^{-}$, the deprotonated form, blue-coloured $\mathrm{BPB}^{-}$and $\mathrm{RNH}_{2}$ is TMA. Other work showed that the indicator responded similarly to ammonia and dimethyl amine. However, in order to simplify the study, this work focussed on the response characteristics of the indicator towards just one of these volatile nitrogen species, namely: TMA. Batch to batch reproducibility of the indicator film was $>95 \%$ and the small difference in colour was attributed to a difference in polymer film thickness, rather than film composition.

\subsection{Methods}

All UV-vis spectra were recorded using a Cary 60 UV-vis spectrophotometer. All digital images were captured using a Canon EOS 700D equipped with an EFS 18-135 mm lens and analysed using freely available software (Fiji ImageJ) [32]. Digital image analysis was carried out by extracting the values of the digital colour defining parameters: Red, Green and Blue, i.e. RGB, each of which lie in the range 0255, from the image of the TVB-N indicator film under test using the ImageJ software [32]. These values were then used to calculate the value of the normalised Blue parameter, $n B$, since here Blue showed the most striking change in colour and value when the indicator is exposed to TMA, where:

$$
n B=B /(R+G+B)
$$

The fish was packaged in a heat-sealed package (dimensions: $180 \times 135 \times 50 \mathrm{~mm}$ ) made of amorphous polyethylene terephthalate (A-PET), using a Mantle Packing Rotopack SVR semi-automatic modified atmosphere tray sealer. The lidding material was PET, with a film thickness of $30 \mu \mathrm{m}$.

\subsection{Sensor Calibration}

In order to measure the sensitivity of the indicator towards TMA, gas mixtures of $\mathrm{N}_{2} / \mathrm{TMA}$, containing different levels of TMA, were generated by bubbling nitrogen gas through a Drechsel bottle containing $100 \mathrm{~cm}^{3}$ aqueous solutions with different wt\% levels of TMA (0.1-4.0 wt\%) The concentration of the TMA in the gas phase for each of these solutions was determined by trapping the TMA in the associated vapour ( 1 hour at a flow rate of $100 \mathrm{~mL} \mathrm{~min}^{-1}$ ) with $100 \mathrm{~cm}^{3}$ of a $0.5 \mathrm{M}$ boric acid and then 
titrating the latter with $0.01 \mathrm{M} \mathrm{NaOH}$ [15]. Thus, for example, a typical experiment revealed that a 4 wt\% aqueous solution of trimethyl amine (TMA) yielded a gas-phase concentration of TMA of 0.125 $\mathrm{mM}$. The same TMA amine vapours were then flowed through a gas cell placed in a UV-vis absorption spectrophotometer, containing a $25 \mathrm{~mm}$ disc of the plastic film BPB indicator, which allowed the spectral changes of the TVB-N indicator to be recorded as a function of exposure time for each of the TMA vapours tested. This data then allowed the construction of a calibration graph of the absorbance of the TVB-N film at $605 \mathrm{~nm}$ (due to the blue coloured deprotonated form of BPB, i.e. BPB') after $2 \mathrm{~h}$ as a function of the concentration of TMA in the vapour, i.e. [TMA] vap.

\subsection{Microbiology}

All solutions for microbiological detection were prepared fresh and sterilised in an autoclave prior to use. A soybean casein lecithin polysorbate culture medium broth (SCDLP) and agar solution were prepared as described elsewhere [33]. The agar solution was sterilised in an autoclave, after which it was carefully poured into standard count plates (approximately $25 \mathrm{~cm}^{3}$ per plate) before being left to $\mathrm{cool}$ and set at room temperature. The agar plates were stored in the fridge at $4^{\circ} \mathrm{C}$ when not in use, and allowed to reach room temperature prior to being used.

The fish was cut into $100 \mathrm{~g}$ fillets which were then placed into individual $180 \times 135 \times 50 \mathrm{~mm}$ plastic trays which were then sealed in air with a PET plastic lid. 2 identical sets of the $100 \mathrm{~g}$ packaged cod fillets were kept at $22^{\circ} \mathrm{C}$, one containing the TVB-N indicator film (which was photographed), and the other one was sampled for microbiological testing; both photography and sampling were carried out regularly and at the same time, $t$, after the initial sealing of the package. In the latter work, at each time interval, a $10 \mathrm{~g}$ sample of the fish was taken aseptically from the package (which was then resealed) and mashed into $10 \mathrm{~cm}^{3}$ of SCDLP solution. Six, ten-fold serial dilutions of the SCDLP/fish extract were then made using saline solution and $0.1 \mathrm{~cm}^{3}$ of the final diluted sample were added to sterile petri plates containing ca. $25 \mathrm{~cm}^{3}$ standard plate count agar, and spread using an L-spreader. After 10 minutes of drying, the plates were incubated at $37^{\circ} \mathrm{C}$ for 24 hours. The colony forming units (cfu's) were then counted to determine the original microbial content of the fish (units: colony forming units (cfu) per $\mathrm{cm}^{3}$ ) for time, $t$, after the initial sealing. The whole procedure was then repeated but this time at $4{ }^{\circ} \mathrm{C}$, rather than at room temperature, i.e. $22^{\circ} \mathrm{C}$. 


\section{Results and Discussion}

The TVB-N plastic film indicator, the preparation of which is described in section 2.3 , was first tested for response to TMA vapours of different concentrations and then used to monitor fish spoilage at two different temperatures, namely, 22 and $4{ }^{\circ} \mathrm{C}$, respectively, in order to explore the extent its response correlates with TVC level. The results of this work, and some additional experiments on dye leaching, are described and discussed in the following sections.

\subsection{Correspondence between Indicator absorbance and colour analysis measurements}

As noted earlier, with colour-based indicators absorbance measurements are highly desirable given that they can be used to probe reaction (1) in a more analytical manner, by providing a measure of the relative values of the $\left[\mathrm{DH}^{-}\right]$and $\left[\mathrm{D}^{-}\right]$, where, in this work, $\mathrm{DH}$ and $\mathrm{D}^{-}$are, respectively, the protonated and deprotonated forms of the $\mathrm{pH}$ indicator dye BPB. In contrast, digital photography, coupled with colour analysis, is a less expensive and a more suitable technique for monitoring the response of colour-based indicators in situ, i.e. inside the package. However, as noted earlier, it is not often that the relationship between these two experimental parameters, i.e. absorbance and digital image RGB colour analysis derived values, like $n B$ in this work, is explored and exploited so as to allow a more rigorous quantitative analysis of the system, although there is increasing interest to do so $[9,34,35]$ and is the basis of this initial investigation of the optical response of the TVB-N plastic film indicator to TMA vapour.

The absorbance spectrum of a standard TVB-N plastic indicator film was monitored using UV-vis spectrophotometry, and photographically, as a function of time at room temperature $\left(22^{\circ} \mathrm{C}\right)$, over a period of $120 \mathrm{~min}$, following its exposure to the amine rich vapour above a $4 \mathrm{wt} \%$ aqueous solution of trimethyl amine (TMA); as noted earlier under these conditions the measured value of the [TMA] $]_{\text {vap }}$ is $0.125 \mathrm{mM}$ TMA. The recorded changes in absorption spectrum, and in appearance of the TVB-N plastic film indicator, as a function of exposure time are illustrated in figure 1(a). The observed colour changes are due to reaction (1), or more precisely, so as to reflect the actual amine and $\mathrm{pH}$ indicator dye used:

$$
\mathrm{HBPB}+\mathrm{N}\left(\mathrm{CH}_{3}\right)_{3} \rightleftharpoons \mathrm{N}\left(\mathrm{CH}_{3}\right)_{3} \mathrm{HN}^{+} \mathrm{BPB}^{-}
$$

Thus, the initial yellow protonated form of BPB in the TVB-N indicator film, HBPB, which has an absorption spectrum wavelength maximum $\left(\lambda_{\max }\right)$ at $450 \mathrm{~nm}$ is slowly, over $2 \mathrm{~h}$, converted to its blue deprontonated form, $\lambda_{\max }=605 \mathrm{~nm}$, due to the equilibrium reaction (3). The sluggish response of the TVB-N plastic film indicator, i.e. ca. $120 \mathrm{~min}$, is attributed to the low permeability of TMA in low density 
polyethylene, coupled with the relatively thick $(\sim 42 \mu \mathrm{m})$ nature of the plastic film.

a.

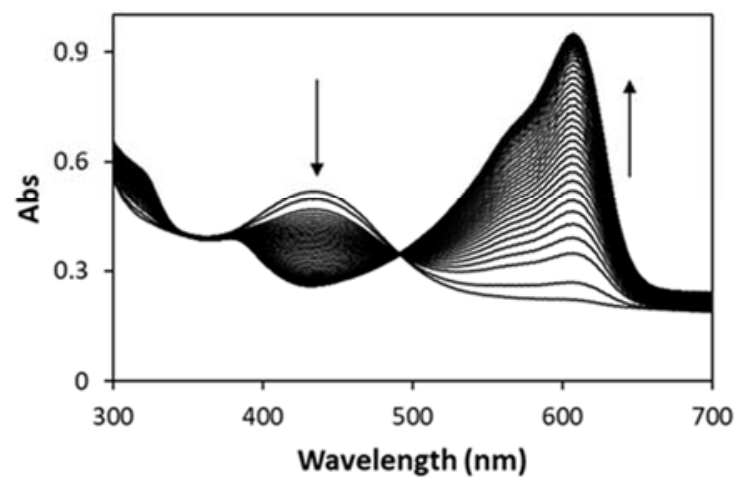

b.

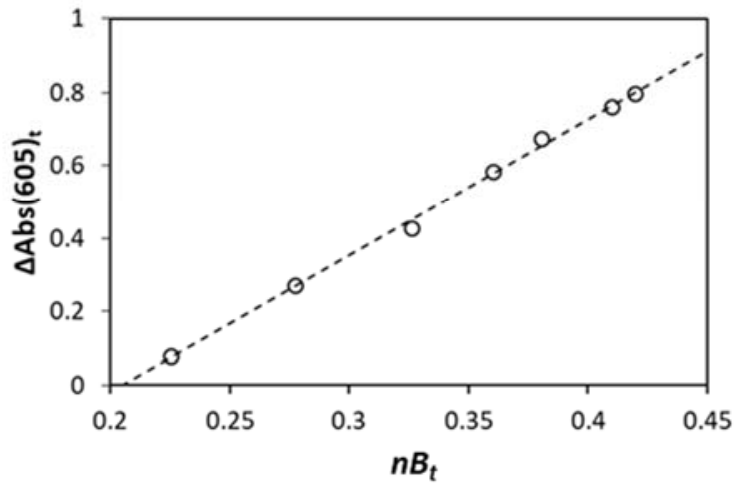

Figure 1 - (a.) Absorbance spectra of a typical TVB-N plastic indicator film (ca. $42 \mu \mathrm{m}$ ), showing the conversion of the original yellow-coloured film to blue (also shown as a series of digital images above the graph) upon exposed to a $0.125 \mathrm{mM}$ TMA vapour; the spectra were recorded every minute; (b) plot of the change in the absorbance at $605 \mathrm{~nm}, \triangle \mathrm{Abs}(605)_{\mathrm{t}}$, calculated using the absorbance data in (a) as a function the normalised RGB blue parameter, $n B_{t}$, values for which were calculated using the $R, G$ and $B$ values extracted from the digital images of the TVB-N indicator illustrated in (a).

The spectral changes illustrated in figure 1(a) allow the change in absorbance at $605 \mathrm{~nm}$, i.e. $\Delta \mathrm{Abs}(605)_{\mathrm{t}}$, to be determined as a function of TMA vapour exposure time, $t$, where $\Delta A b s(605)_{t}$ is the difference in absorbance at $605 \mathrm{~nm}$ at time, $t$, and that at $\mathrm{t}<0$, i.e. before exposure, when no $\mathrm{BPB}^{-}$is present. Note: from Beer's law, $\triangle \mathrm{Abs}(605)_{\mathrm{t}}$ is proportional to $\left[\mathrm{BPB}^{-}\right]$, or more precisely, $\left[\mathrm{N}\left(\mathrm{CH}_{3}\right]_{3} \mathrm{HN}^{+} \mathrm{BPB}-\right]$, in reaction (3). Similarly, $\mathrm{RGB}$ colour analysis of the digital photographs illustrated in figure 1 (a) allow the value of $n B_{t}$ to be determined and the plot of $\Delta \mathrm{Abs}(605)_{\mathrm{t}} \mathrm{vs.} n B_{t}$, illustrated in figure $1(b)$, reveals a simple, direct relationship between these two optical parameters, indicating that

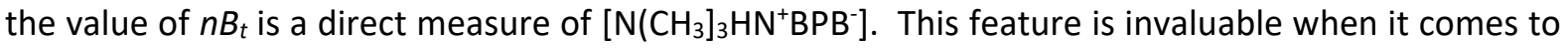
using the TVB-N indicator in food packaging, where recording the UV-vis absorption spectrum is no longer practical, but where a quantitative method for determining the concentration of $\left[\mathrm{N}\left(\mathrm{CH}_{3}\right)_{3} \mathrm{HN}^{+} B P B-\right]$ is required.

\subsection{TVB-N indicator calibration}

The optical response of the TVB-N indicator plastic film was then probed as function the level of TMA in the gas phase, $[\mathrm{TMA}]_{\text {vap }}$. The latter parameter was varied by filling a Drechsel bottle with different wt.\% dilute TMA solutions ( $0-4 \mathrm{wt} \%)$, and bubbling a continuous stream of nitrogen $\left(100 \mathrm{~mL} \mathrm{~min}{ }^{-1}\right)$ through each solution. Each gas stream, produced in this manner, with its different level of TMA in the vapour phase, i.e. $[T M A]_{\text {vap }}$, was then flowed through an optical gas cell, placed in a UV-vis spectrophotometer containing the TVB-N indicator. Figure 2(a) illustrates the resulting Abs(605) $\mathrm{t} v \mathrm{~s}$ 
time plots determined using the TVB-N indicator when exposed to the different TMA levels in the vapour phase. These results show that within $2 \mathrm{~h}$ of exposure to each TMA vapour, the colour (and so absorbance) of the indicator attains a steady state value, a measure of which is Abs(605) eq and a feature that is consistent with the equilibrium nature of reaction (3).

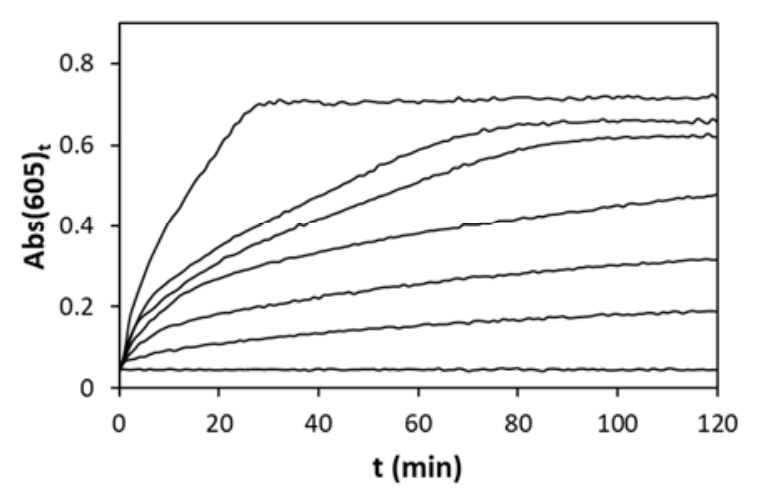

b.

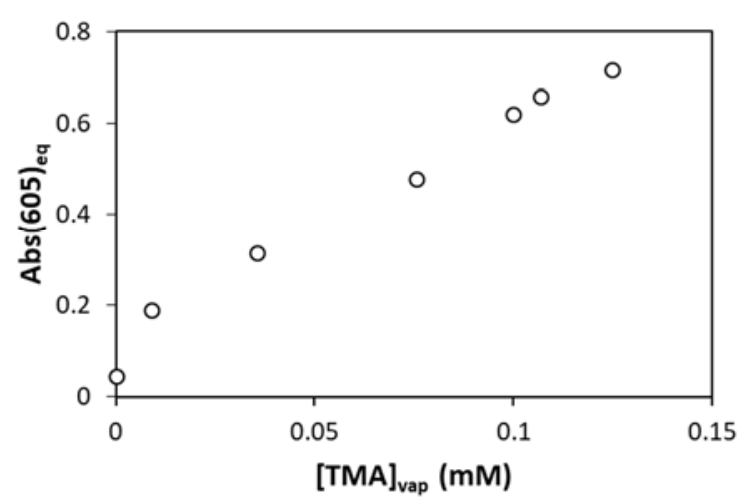

Figure 2 - (a.) Colour change profiles at $605 \mathrm{~nm}$ for TVB-N plastic film after exposure to trimethyl amine vapour of different concentrations; which were (from bottom to top: $0,0.01,0.036,0.076,0.1,0.107$ and $0.125 \mathrm{mM}$, respectively, as determined by acidimetric titration, and (b.) a plot of Abs(605) vs. [TMA] vap (mM).

As outlined in the Experimental section 2.5, other experiments were carried out to measure [TMA] $]_{\text {vap,, }}$ i.e. the different levels of TMA in the vapour phase, when $\mathrm{N}_{2}$ was bubbled through the Drechsel bottle with the different wt.\% dilute TMA solutions $(0-4 \mathrm{wt} \%)$. These two data sets were then combined to generate the plot of $A b s(605)_{\text {eq }}$ vs [TMA] vap, illustrated in figure 2(b), which yielded a straight line, thereby indicating that $\mathrm{Abs}(605)_{\mathrm{eq}}$, and therefore $\left[\mathrm{N}\left(\mathrm{CH}_{3}\right]_{3} \mathrm{HN}^{+} \mathrm{BPB}\right]$, is directly proportional to $[T M A]_{\text {vap }}$. It follows from the work in section 3.1 that $n B$ will also be proportional to [TMA $]_{\text {eq }}$ and suggests that the more convenient and simple to measure colour analysis parameter, $n B$, can be used as a measure of fish freshness for packaged fish, since others have shown that there is a direct correlation between fish freshness, as measured by TVB-N in fish, or spoilage bacterial levels and the level of TVB-N in the package headspace [36, 37]. This latter finding is not too surprising given that fish freshness is already routinely linked to the level of TVB-N in the fish itself $[14,17,25]$.

\subsection{TVB-N indicator and fish spoilage}

In order to test how well the TVB-N indicator responds to packaged fish spoiling at room temperature, i.e. $22^{\circ} \mathrm{C}$, a $25 \mathrm{~mm}$ diameter disc of the plastic film was stuck to the inside of the lidding of a package containing $100 \mathrm{~g}$ of fresh cod, which was then sealed. Photographs of the indicator were taken immediately after packaging, and then every hour for 36 hours. The photographs illustrated in figure 3 show that a clear colour change, from yellow to blue, is observed in the TVB-N indicator as the fish spoils and takes on a slightly waxy appearance. 

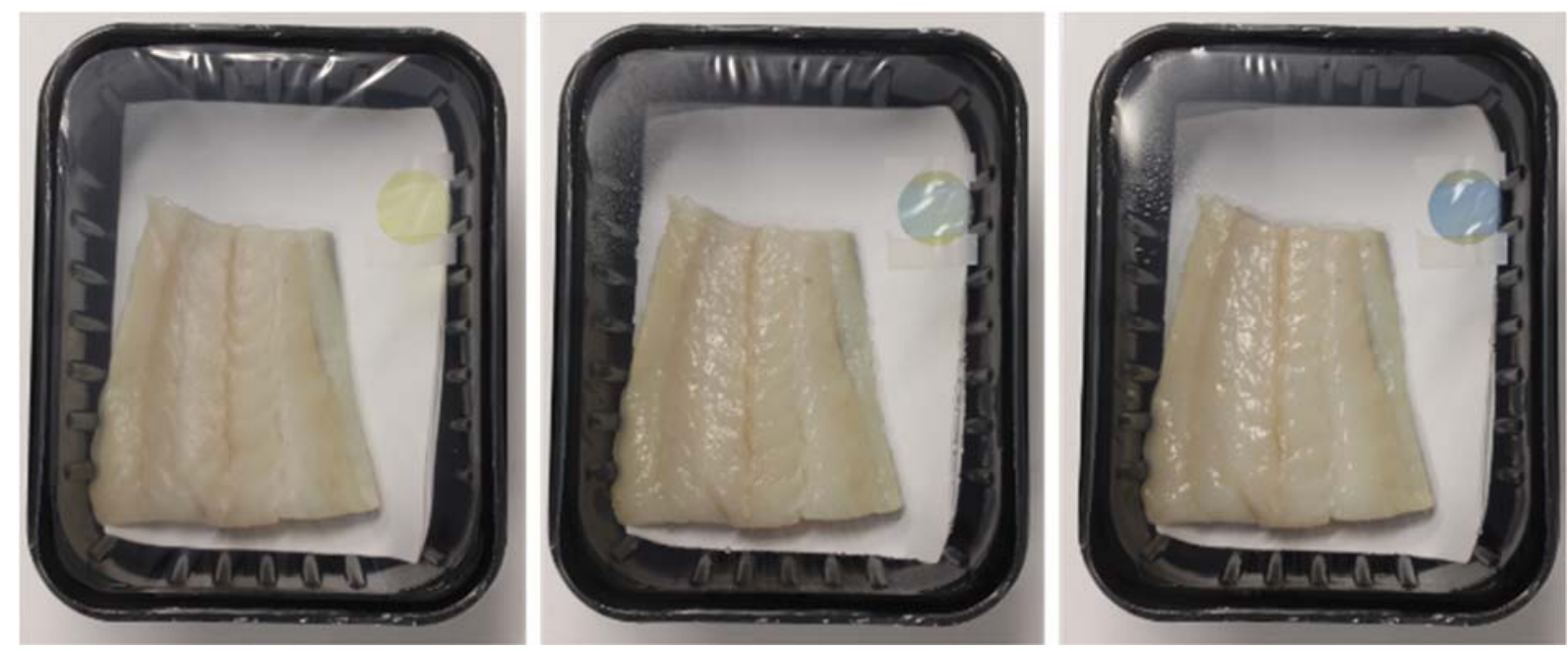

(a)

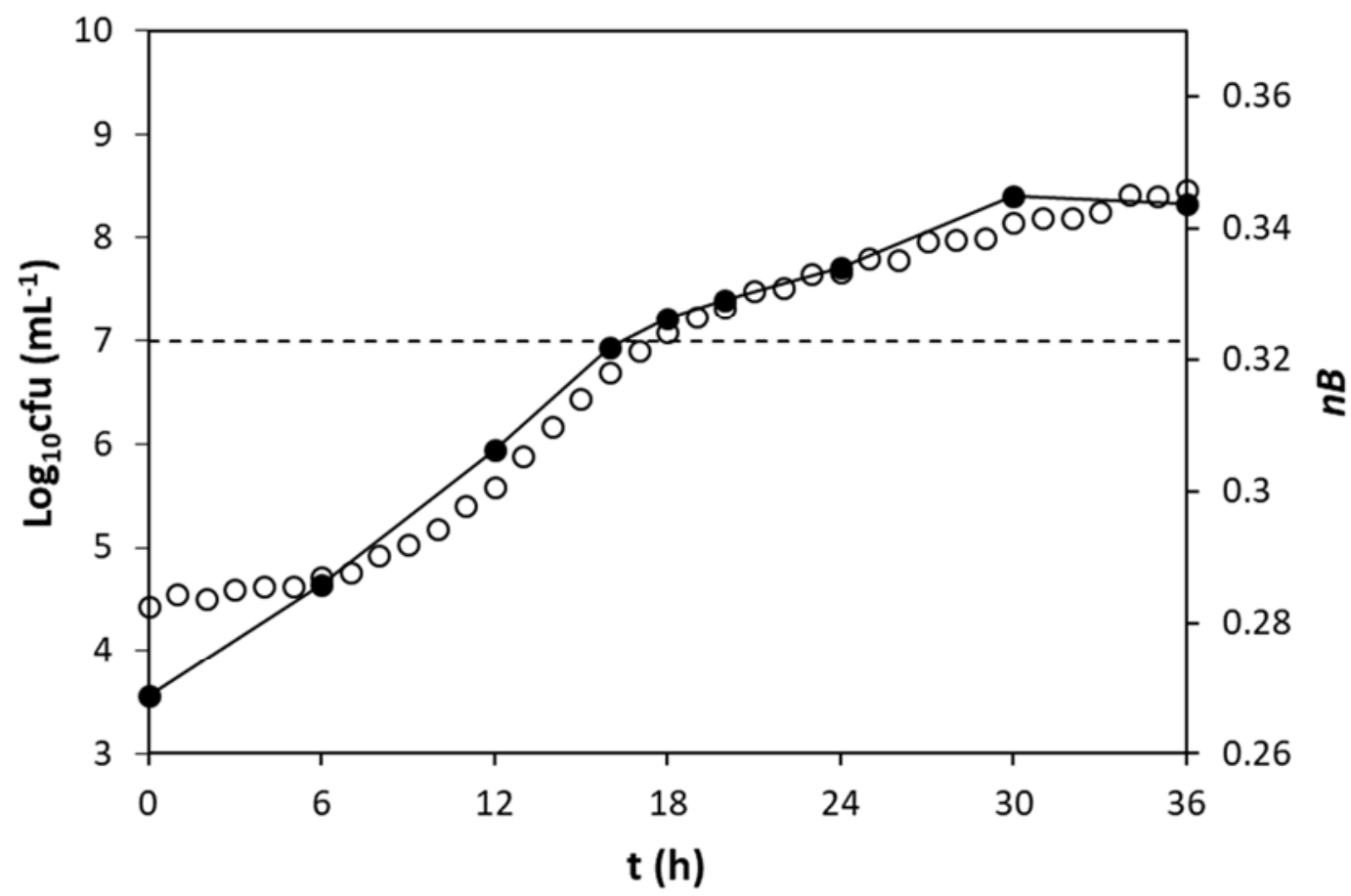

(b)

Figure 3 (a) Digital images of the indicator film packaged above cod at (left) 0, (centre) 24, and (right) 48 hours at room temperature $\left(22^{\circ} \mathrm{C}\right)$ and $(\mathrm{b})$ plot of the measured (closed circles) cfu levels in cod flesh and (open circles) concomitant colour change of the indicator, i.e. $n B$, as a function of storage package time at $22^{\circ} \mathrm{C}$.

RGB Colour analysis of the photographs taken of the indicator as a function of storage time generated a series of $n B$ values for the different package times at $22{ }^{\circ} C^{\prime}$, and a plot of this data is illustrated in 
figure $3(b)$. This colour change is due to the indicator responding to the increase in TVB-N concentration in the headspace, which others $[16,25,36]$ have shown to be correlated directly to fish freshness based on the TVB-N level in fish and the TVC. However, in the past, the quantitative assessment of [TVB-N] in the vapour phase has required an involved analytic procedure, such as the laborious traditional TVB-N titration method [15,36], or expensive GC analysis [38], whereas here we use a simple, inexpensive plastic film TVB-N indicator, with an easily measured optical response, $n B$, which is proportional to [TVB-N] $]_{\text {vap, }}$ and so the level of TVB-N in fish.

As noted previously, the TVB-N levels detected in the headspace of the package by the indicator are due to the TVB-N in the fish which in turn is due to the growth of fish spoilage bacteria. Others have reported that $[\text { TVB-N] }]_{\text {vap }}$ and the fish spoilage bacterial population, as measured by $\log (\mathrm{cfu})$, are directly correlated $[16,25]$. In order to demonstrate this relationship in this work, a microbiological study was carried out under the same conditions as in figure 3(a), in which the bacterial levels, in units of cfu $\mathrm{mL}^{-1}$, in the flesh of the fish were monitored over the same 36 -hour period. The results of this study are also illustrated in figure 3(b) and reveal the expected strong correlation in shape between $n B$ (which provides a direct measure of [TVB-N] vap, see figure $2(b)$, and $\log (\mathrm{cfu})$.

The same set of experiments as outlined above were also conducted at $4{ }^{\circ} \mathrm{C}$ and the results of this work are illustrated in figure 4. Interestingly, the major difference between the two data sets illustrated in figure $3(\mathrm{a})$ and figure 4 , is time scale, in that, at $22^{\circ} \mathrm{C}$, it takes about $18 \mathrm{~h}$ for the bacterial levels in the fish to exceed $10^{7} \mathrm{cfu} \mathrm{mL}^{-1}$, indicated by the horizontal broken line, whereas at $4{ }^{\circ} \mathrm{C}$, it takes nearer 4.5 days. Strikingly, in both cases the $n B$ and $\log (\mathrm{cfu})$ time profiles are strongly correlated. Indeed, an $n B$ value of ca. 0.32 , which is associated with a particular green colouration of the TVB-N indicator, can in both cases be used as an indication that the fish is spoiled and no longer safe to eat. In practice, the identification of this point might be made using a digital mobile photo camera and colour analysis App or, more simply, using a colour matching card. 


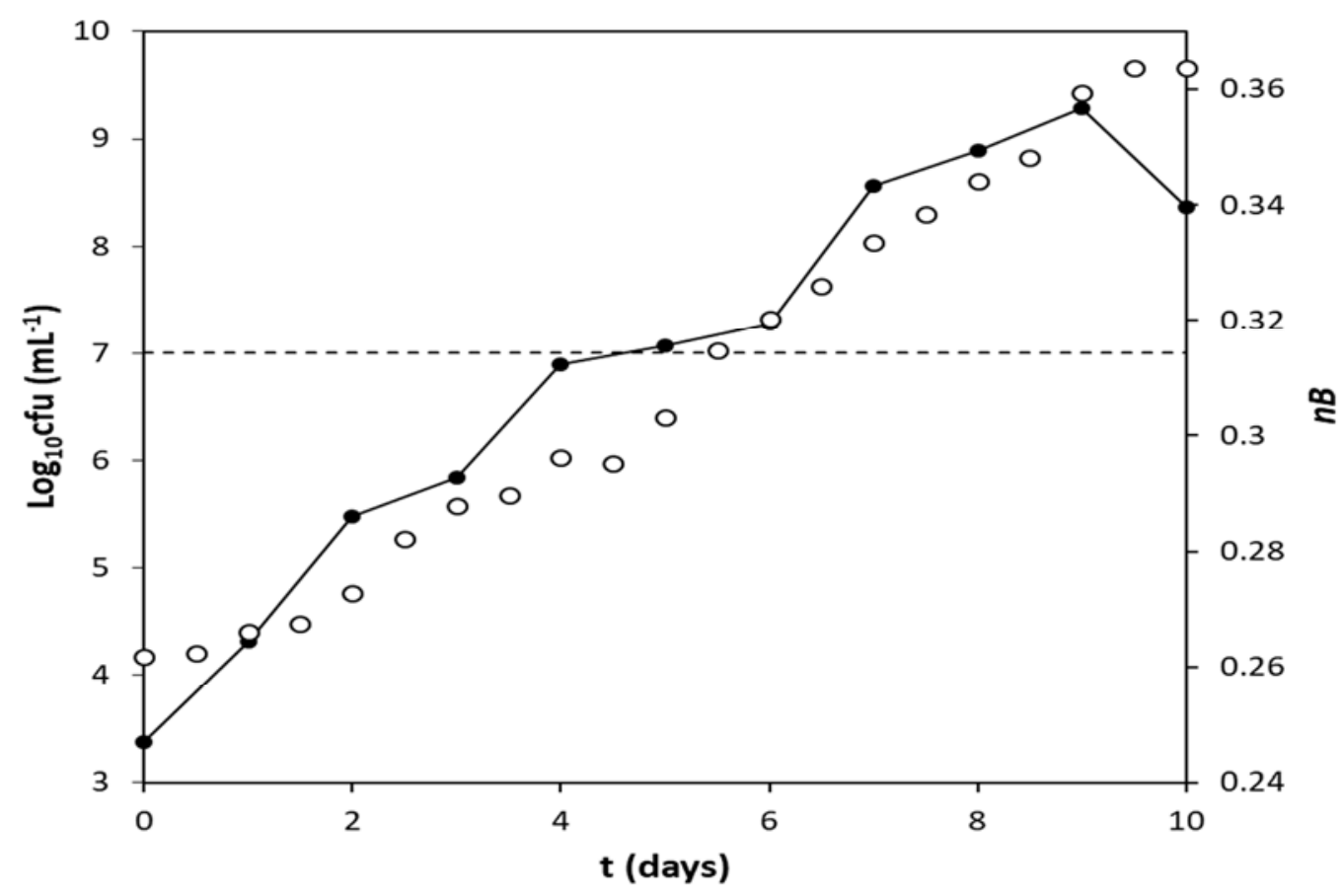

Figure 4 Plot of the measured (closed circles) cfu levels in cod flesh and (open circles) concomitant colour change of the indicator, i.e. $n B$, as a function of storage package time $4{ }^{\circ} \mathrm{C}$.

\subsection{Indicator stability in aqueous solution}

As noted earlier, a key feature of this new plastic TVB-N indicator is that the LDPE should act as a GPM, and protect it from dye leaching and also prevent ingress of hydroxyl ions into the indicator film which would give a false positive response to TVB-N. Given the high water content of fresh fish the presence of water in any package is high and so too, therefore, is the likelihood of water contacting the indicator; thus, the stability of the TVB-N indicator in water is essential. In order to demonstrate this feature the indicator was stored in water for many weeks and exhibited no loss of dye or change in response. In a more demanding test, the indicator was also placed in a highly alkaline solution (0.1 M $\mathrm{NaOH}$ ) and showed no change in colour even after $48 \mathrm{~h}$. In contrast, a traditional ink-based ammonia indicator [19], similar to those reported in Table 1, changed colour (yellow to blue) instantly due to the simple deprotonation reaction:

$$
\underset{\text { Yellow }}{\mathrm{OH}^{-}+\underset{\text { Blue }}{\mathrm{HBPH}}} \underset{\text { Blu }}{\rightleftharpoons}
$$

When a drop of TMA solution is added to the TVB-N plastic film indicator in either aqueous solution 
or the highly alkaline solution, the indicator turned blue immediately due to the TMA vapour diffusing through the gas permeable, but not ion permeable, LDPE GPM. Illustrative photographs of the film in some of these experiments are given in the Supplementary information, figure S3.

\section{Conclusions}

A colourimetric volatile amine sensor which undergoes a colour change from yellow to blue in response to TVB-N in the vapour phase and can be used to indicate the spoilage of fish has been developed. The indicator comprises a $\mathrm{pH}$ indicator, $\mathrm{BPB}$, coated onto fumed silica to create a pigment that can be readily dispersed through a thin film of LDPE via extrusion. The colour change, as measured by absorbance or the normalised colour parameter, $n B$, exhibited by the TVB-N indicator is proportional to the concentration of TVB-N (in the form of TMA) in the headspace. In a study of packaged fresh cod, at room temperature $\left(22^{\circ} \mathrm{C}\right)$ and $4{ }^{\circ} \mathrm{C}$, the colour response of the TVB-N indicator recorded as a function of time, correlates very closely to that the $\log _{10}$ of the measured bacterial colony forming units on the cod. The plastic film TVB-N indicator appears impervious to dye leaching or ion migration, both of which can cause similar ink-based films to fail. These results suggest that the TVB-N plastic indicator film may find application in the fish packaging industry as a food spoilage indicator, especially if combined with a simple colour measuring technique, such as colour analysis coupled to digital photography or, more simply, colour-matching. 


\section{References}

[1] Y.K. L., T.P. T., M. Joseph, Intelligent Packaging: Concepts and Applications, Journal of Food Science, 70 (2005) R1-R10.

[2] K.L. Yam, J.W. Miltz, Intelligent Packaging, in: K.L. Yam (Ed.) The Wiley Encyclopedia of Packaging Technology, Wiley, New York, 2009.

[3] C. Zhang, A.-X. Yin, R. Jiang, J. Rong, L. Dong, T. Zhao, L.-D. Sun, J. Wang, X. Chen, C.-H. Yan, TimeTemperature Indicator for Perishable Products Based on Kinetically Programmable Ag Overgrowth on Au Nanorods, ACS Nano, 7 (2013) 4561-4568.

[4] C. Rukchon, A. Nopwinyuwong, S. Trevanich, T. Jinkarn, P. Suppakul, Development of a food spoilage indicator for monitoring freshness of skinless chicken breast, Talanta, 130 (2014) 547-554.

[5] S.-K. Lee, M. Sheridan, A. Mills, Novel UV-Activated Colorimetric Oxygen Indicator, Chemistry of Materials, 17 (2005) 2744-2751.

[6] A. Pacquit, K.T. Lau, H. McLaughlin, J. Frisby, B. Quilty, D. Diamond, Development of a volatile amine sensor for the monitoring of fish spoilage, Talanta, 69 (2006) 515-520.

[7] G.-Y. Lee, H.-S. Shin, Development of freshness indicator for quality of skate (Raja kenojei) during storage, Food Science and Biotechnology, 25 (2016) 1485-1489.

[8] X.-d. Wang, O.S. Wolfbeis, Optical methods for sensing and imaging oxygen: materials, spectroscopies and applications, Chemical Society Reviews, 43 (2014) 3666-3761.

[9] D. Yusufu, A. Mills, Spectrophotometric and Digital Colour Colourimetric (DCC) analysis of colourbased indicators, Sensors and Actuators B: Chemical, 273 (2018) 1187-1194.

[10] Y.H. Kim, Y.J. Yang, J.S. Kim, D.S. Choi, S.H. Park, S.Y. Jin, J.S. Park, Non-destructive monitoring of apple ripeness using an aldehyde sensitive colorimetric sensor, Food Chemistry, 267 (2018) 149-156. [11] A. Pacquit, K. Crowley, D. Diamond, Smart Packaging Technologies for Fish and Seafood Products, in: J.P. Kerry, P. Butler (Eds.) Smart Packaging Technologies for Fast Moving Consumer Goods2008.

[12] A. Pacquit, J. Frisby, D. Diamond, K.T. Lau, A. Farrell, B. Quilty, D. Diamond, Development of a smart packaging for the monitoring of fish spoilage, Food Chemistry, 102 (2007) 466-470.

[13] P. Zaragozá, S. Ribes, A. Fuentes, J.-L. Vivancos, I. Fernández-Segovia, J.V. Ros-Lis, J.M. Barat, R. Martínez-Máñez, Fish Freshness Decay Measurement with a Colorimetric Array, Procedia Engineering, 47 (2012) 1362-1365.

[14] Commission Regulation (EC) No 1022/2008, 2008. Last accessed November 2018

[15] https://www.fsai.ie/uploadedFiles/Consol Reg2074 2005.pdf. Last accessed November 2018

[16] M.T. Veciana-Nogués, A. Mariné-Font, M.C. Vidal-Carou, Biogenic Amines as Hygienic Quality Indicators of Tuna. Relationships with Microbial Counts, ATP-Related Compounds, Volatile Amines, 
and Organoleptic Changes, Journal of Agricultural and Food Chemistry, 45 (1997) 2036-2041.

[17] M.K. Morsy, K. Zór, N. Kostesha, T.S. Alstrøm, A. Heiskanen, H. El-Tanahi, A. Sharoba, D. Papkovsky, J. Larsen, H. Khalaf, M.H. Jakobsen, J. Emnéus, Development and validation of a colorimetric sensor array for fish spoilage monitoring, Food Control, 60 (2016) 346-352.

[18] C.A.M.L. dos Santos, D. James, F. Teutscher, Guidelines for chilled fish storage experiments, FAO, Rome, 1981.

[19] A. Mills, L. Wild, Q. Chang, Plastic colorimetric film sensors for gaseous ammonia, Microchimica Acta, 121 (1995) 225-236.

[20] T. Werner, I. Klimant, O.S. Wolfbeis, Ammonia-sensitive polymer matrix employing immobilized indicator ion pairs, Analyst, 120 (1995) 1627-1631.

[21] https://en.wikipedia.org/wiki/CIELAB color space. Last accessed November 2018

[22] https://en.wikipedia.org/wiki/Color difference. Last accessed November 2018

[23] H.-N. Chun, B. Kim, H.-S. Shin, Evaluation of a freshness indicator for quality of fish products during storage, Food Science and Biotechnology, 23 (2014) 1719-1725.

[24] G.-Y. Lee, S. Lee, H.-S. Shin, Evaluation of gas freshness indicator for determination of skate (Raja kenojei) quality during storage, Food Science and Biotechnology, 25 (2016) 1497-1500.

[25] M. Majdinasab, S.M.H. Hosseini, M. Sepidname, M. Negahdarifar, P. Li, Development of a novel colorimetric sensor based on alginate beads for monitoring rainbow trout spoilage, Journal of Food Science and Technology, 55 (2018) 1695-1704.

[26] https://www.manitoba.ca/agriculture/about/index.html Manitoba Agriculture. Last accessed November 2018

[27] A. Mills, D. Yusufu, Extruded colour-based plastic film for the measurement of dissolved CO2, Sensors and Actuators B: Chemical, 237 (2016) 1076-1084.

[28] G. Neurauter, I. Klimant, O.S. Wolfbeis, Fiber-optic microsensor for high resolution pCO2 sensing in marine environment, Fresenius' Journal of Analytical Chemistry, 366 (2000) 481-487.

[29] https://www.insigniatechnologies.com/home.php?video=1 Insignia Technologies Ltd. Last accessed November 2018

[30] D. Yusufu, C. Wang, A. Mills, Evaluation of an 'After Opening Freshness (AOF)' label for packaged ham, Food Packaging and Shelf Life, 17 (2018) 107-113.

[31] A. Niazi, J. Zolgharnein, M.R. Davoodabadi, Spectrophotometric determination of acidity constant of some indicators in various micellar media solutions by rank annihilation factor analysis, Spectrochim Acta A Mol Biomol Spectrosc, 70 (2008) 343-349.

[32] https://fiji.sc/. Last accessed November 2018

[33] http://www.scharlabmagyarorszag.hu/katalogus/02-613 TDS EN.pdf. Last accessed November 
2018

[34] T.R. Knutson, C.M. Knutson, A.R. Mozzetti, A.R. Campos, C.L. Haynes, R.L. Penn, A Fresh Look at the Crystal Violet Lab with Handheld Camera Colorimetry, Journal of Chemical Education, 92 (2015) 1692-1695.

[35] D.L. Williams, T.J. Flaherty, C.L. Jupe, S.A. Coleman, K.A. Marquez, J.J. Stanton, Beyond $\lambda[$ lambda]max: Transforming Visible Spectra into 24-Bit Color Values, Journal of Chemical Education, 84 (2007) 1873.

[36] C. Zhao, Y. Pan, L. Ma, Z. Tang, G. Zhao, L. Wang, Assay of fish freshness using trimethylamine vapor probe based on a sensitive membrane on piezoelectric quartz crystal, Sensors and Actuators B: Chemical, 81 (2002) 218-222.

[37] L.-Y. Chang, M.-Y. Chuang, H.-W. Zan, H.-F. Meng, C.-J. Lu, P.-H. Yeh, J.-N. Chen, One-Minute Fish Freshness Evaluation by Testing the Volatile Amine Gas with an Ultrasensitive Porous-ElectrodeCapped Organic Gas Sensor System, ACS Sensors, 2 (2017) 531-539.

[38] R. Lv, X. Huang, J.H. Aheto, L. Mu, X. Tian, Analysis of fish spoilage by gas chromatography-mass spectrometry and electronic olfaction bionic system, Journal of Food Safety, 0 e12557. 